\title{
An Analysis of a Severe Turbulence Event Encountered by an Aircraft over the South China Sea and the Application of Numerical Weather Prediction Models in the Early Alerting of the Event
}

\author{
P. W. Chan and W. K. Wong \\ Hong Kong Observatory, 134A Nathan Road, Kowloon, Hong Kong \\ Correspondence should be addressed to P. W. Chan; pwchan@hko.gov.hk
}

Received 17 January 2014; Accepted 15 March 2014; Published 10 April 2014

Academic Editor: Hiroyuki Hashiguchi

Copyright (C) 2014 P. W. Chan and W. K. Wong. This is an open access article distributed under the Creative Commons Attribution License, which permits unrestricted use, distribution, and reproduction in any medium, provided the original work is properly cited.

\begin{abstract}
In the literature, there is rather limited number of accounts of significant turbulence over the South China Sea, which is an area of busy air traffic. The present paper documents the meteorological observations of an aircraft over the seas west of the Philippines on encountering severe turbulence associated with an area of convection. From the valuable flight data available from this aircraft, it is found that, on encountering the significant turbulence, the aircraft experienced increase in wind speed, strong downdraft, high windshear hazard factor, and, most importantly, high level of eddy dissipation rate, which is a measure of turbulence intensity in civil aviation. The application of numerical weather prediction (NWP) models in the forecasting of this severe turbulence case is also studied. It turns out that the cumulonimbus extent and in-cloud turbulence potential products from World Area Forecast System may have some indication of the occurrence of significant turbulence associated with convection in the area concerned. A mesoscale NWP model even forecasts the possibility of moderate-to-severe turbulence about 24 to 27 hours ahead of the event.
\end{abstract}

\section{Introduction}

The northern and central parts of the South China Sea are areas of busy air traffic. They are also in an area of intense convection associated with the Intertropical Convergence Zone (ITCZ). However, the number of turbulence reports on record over this area is rather small. Records are available at parts of the South China Sea, for instance, over the Hong Kong Flight Information Region (HKFIR). Taking the period between January 2008 and December 2009 as an example, there were a total number of 168 reports of moderate or greater turbulence over the total number of flights of 879,130 in the region, namely, a percentage of 0.02 . It is even more rare to have the flight data from an aircraft encountering severe turbulence that could be used for further analysis of the nature of the turbulence.

Occurrence of clear air turbulence in the tropics has been reported in Roach and Bysouth [1]. Severe turbulence in the significant convection over the tropics has been observed in the radar as reported in Rao et al. [2]. Ahmad and Proctor [3] studied some convection induced turbulence cases using large eddy simulations and found that there were areas of significant turbulence upwind of the convection in the upper level of the troposphere.

An event of severe turbulence was recorded by an A320 aircraft flying from Malaysia to Hong Kong, China, at about 1345 UTC, 9 August 2013. It occurred over the South China Sea to the west of the Philippines. Some crew members were injured during the event. The aircraft lost a height of about 1000 feet when encountering the severe turbulence. Quick assess recorder (QAR) data were available from this flight. It is unusual that flight data are available for an aircraft encountering severe turbulence over the South China Sea.

This paper aims at documenting the meteorological conditions and observations from the flight data in such a severe turbulence event. Moreover, the application of numerical 


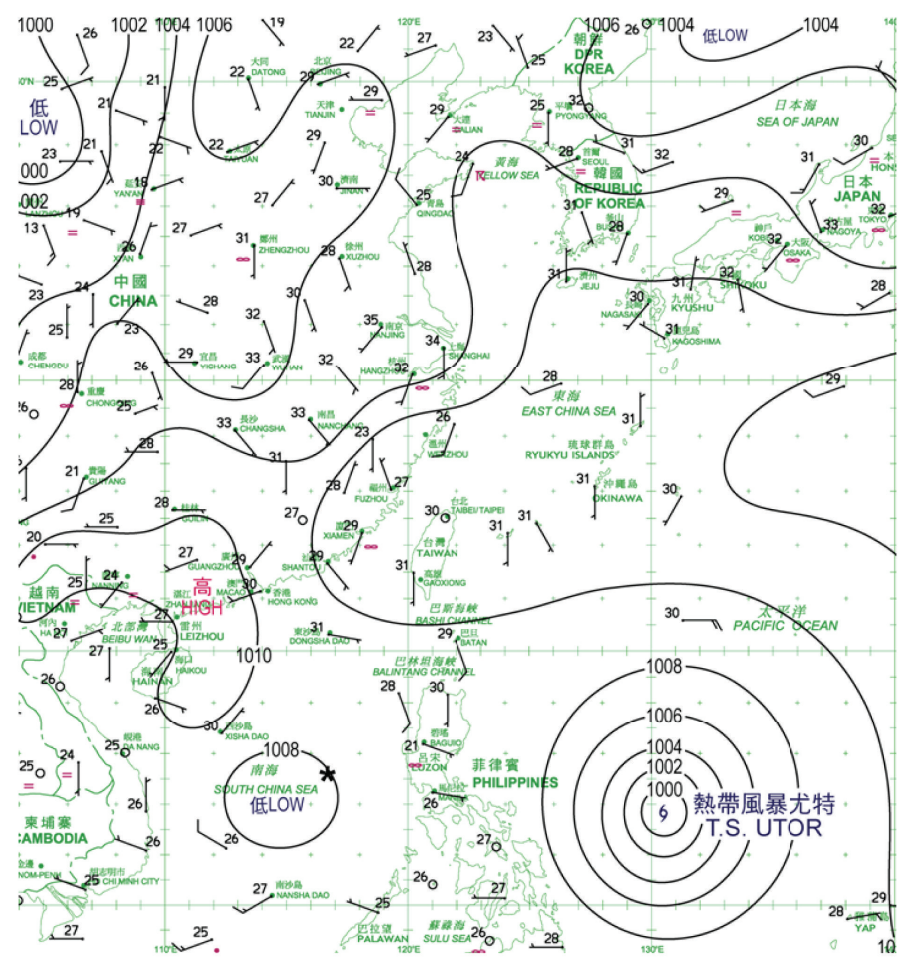

FIgURE 1: Surface isobaric chart at 00 UTC, 10 August 2013. The asterisk shows the location of the severe turbulence event.

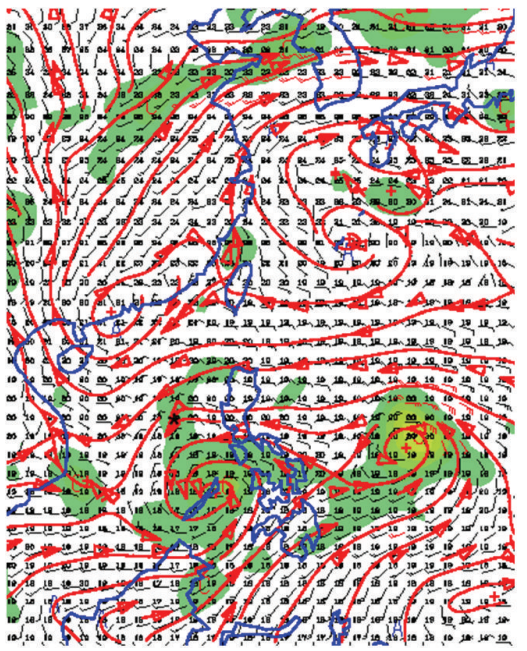

(a) $850 \mathrm{hPa}$ wind with vorticity (shaded)

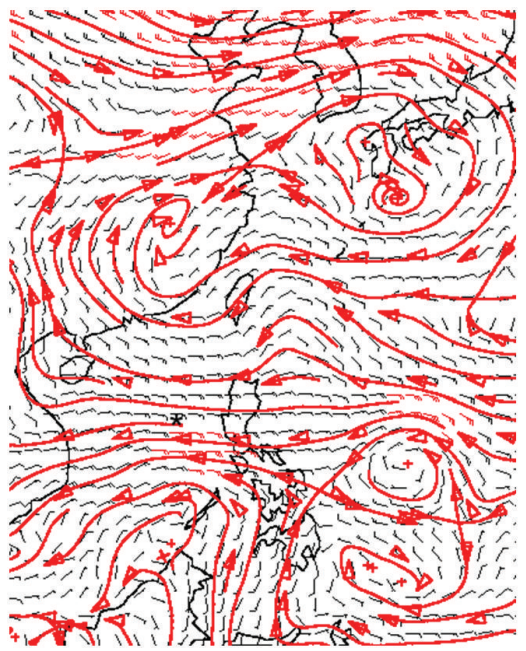

(b) $500 \mathrm{hPa}$ wind

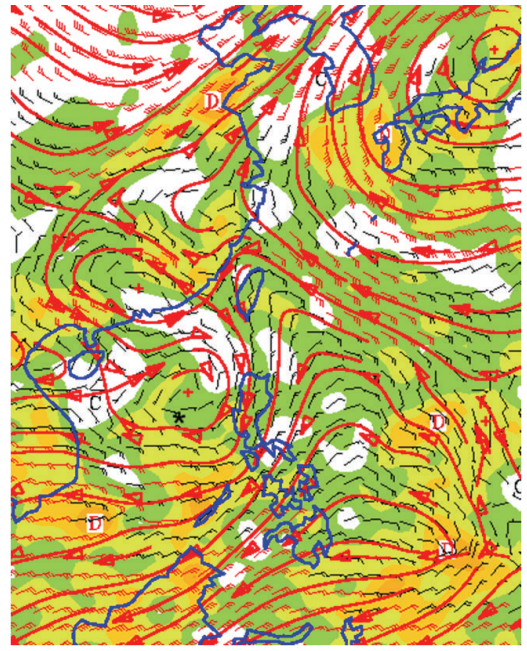

(c) $200 \mathrm{hPa}$ wind with divergence (shaded)

FIGURE 2: Upper-air analysis from JMA global model. The asterisk shows the location of the severe turbulence event.

weather prediction (NWP) models in the forecasting of the turbulence encounter will be discussed.

\section{Synoptic Overview}

From the surface isobaric chart in the morning following the event (00 UTC, 10 August 2013, Figure 1), an area of low pressure could be analyzed over the central part of the South China Sea to the west of the Philippines. At the same time, there was Tropical Storm Utor at about the same latitude to the east of the Philippines.

Upper-air analysis at a time rather close to the event time, namely, 12 UTC, 9 August 2013, was obtained from the global model analysis from Japan Meteorological Agency. The analysis at 850,500 , and $200 \mathrm{hPa}$ is shown in Figure 2. It could be seen that there was cyclonic flow in the lower and middle troposphere. At the same time, divergence associated with northeasterly flow could be analyzed at $200 \mathrm{hPa}$. The lower 


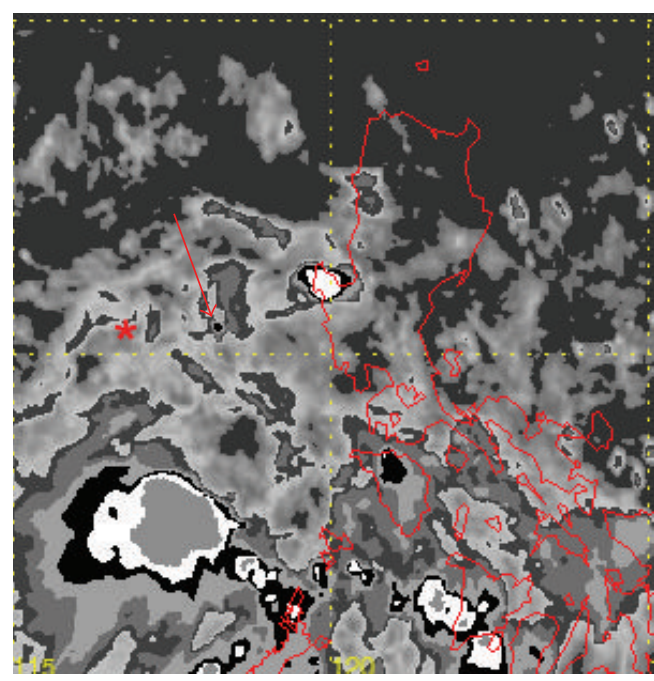

(a) 0932 UTC

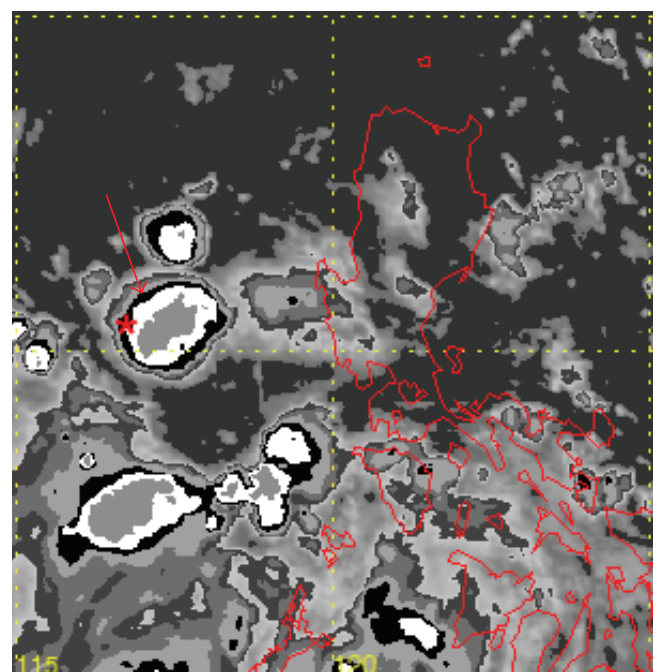

(c) 1332 UTC

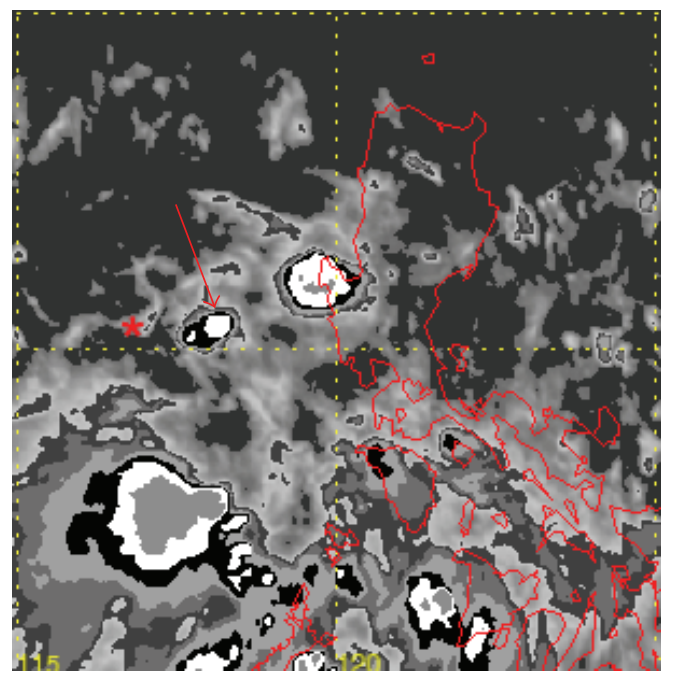

(b) 1032 UTC

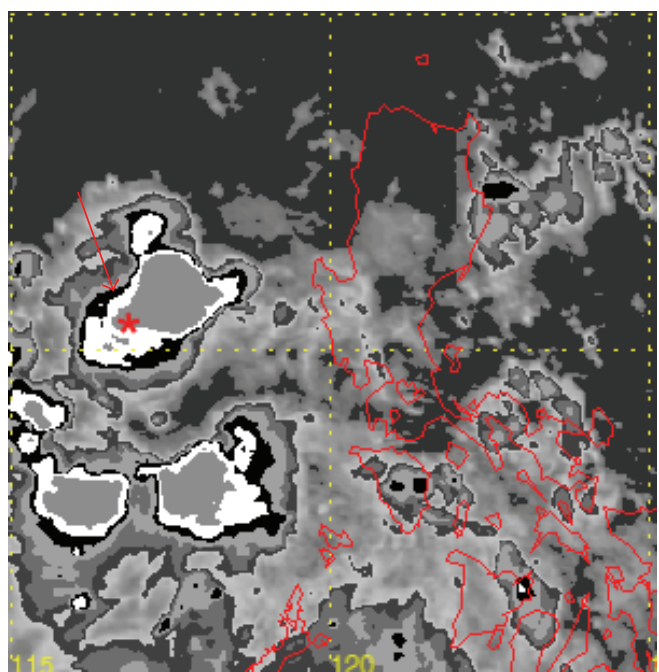

(d) 1532 UTC

FIGURE 3: Infrared satellite pictures from MTSAT over the area of severe turbulence before and after the event. The convection under consideration is highlighted by a red arrow. The asterisk shows the location of the severe turbulence event. The satellite images are shown using the colour scale of Dvorak analysis.

level cyclonic flow and the upper level divergence supported the occurrence of intense convection over the seas to the west of the Philippines.

\section{Satellite Observation from MTSAT (Multifunctional Transport Satellite of Japan Meteorological Agency)}

Infrared satellite imagery about the event time could be found in Figure 3. The images are presented using the colouring scheme of Dvorak analysis [4]. At about 0932 UTC, 9 August 2013, a tiny bit of significant convection began to develop at the event area. In the next few hours, the convection developed further and grew in size. The cloud top became cooler and the convection showed further sign of development after the event (e.g., the satellite picture at 1532 UTC, 9 August).
It could be seen that the turbulence event occurs at the boundary of the very significant convection (coloured grey as in Figure 3).

At the time of the event (1332 UTC, 9 August), the cloud top temperature at the event area was around 236 degrees $\mathrm{K}$. According to the radiosonde ascent in Hong Kong at 12 UTC, 9 August 2013, this corresponds to a height of about 10,600 m, that is, reaching the FL340 (flight level at 34,000 feet). It is not assured if the pilot could see the convection and the severe turbulence from the onboard radar because there was no record of the radar picture/data.

\section{Aircraft Data}

The QAR data of the event are given in Figure 4. The data have been analyzed by using the software of Haverdings and Chan 


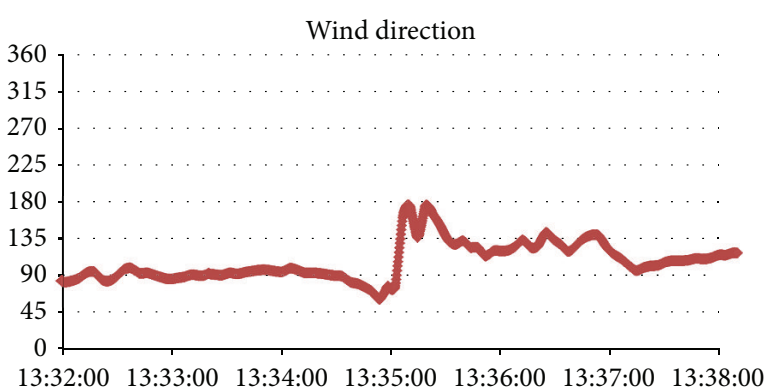

(a)

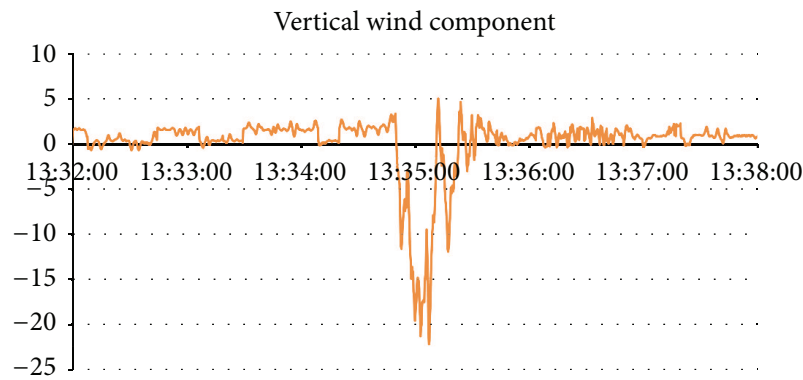

(c)

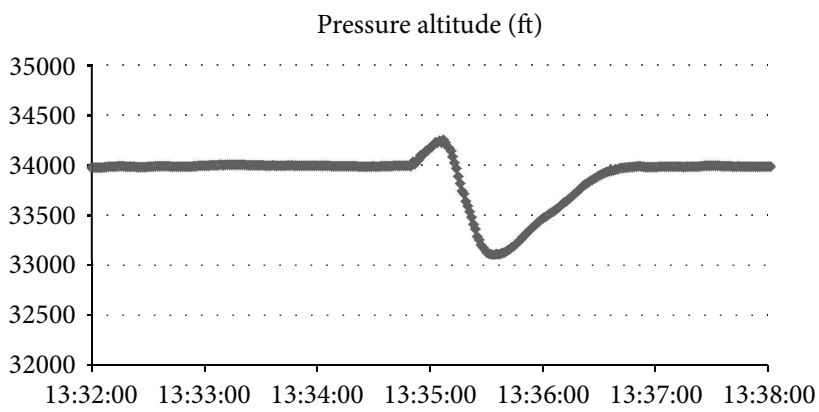

(e)

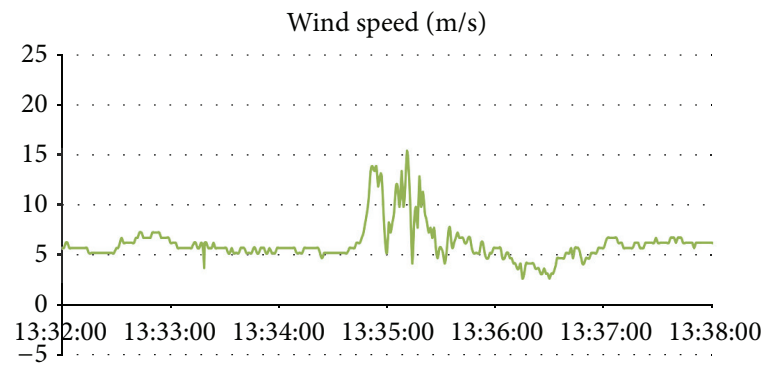

(b)

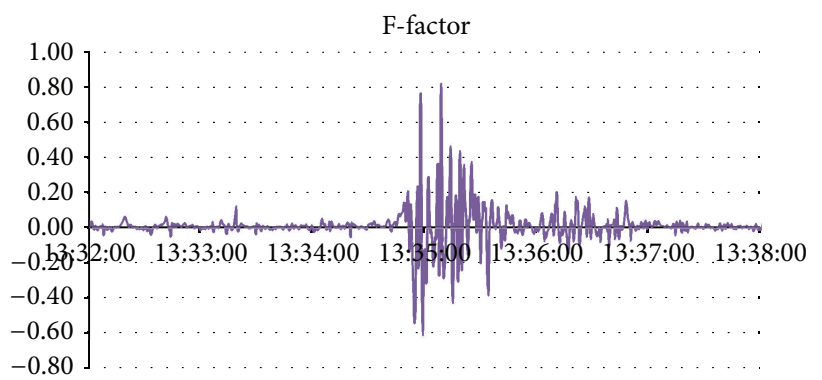

(d)

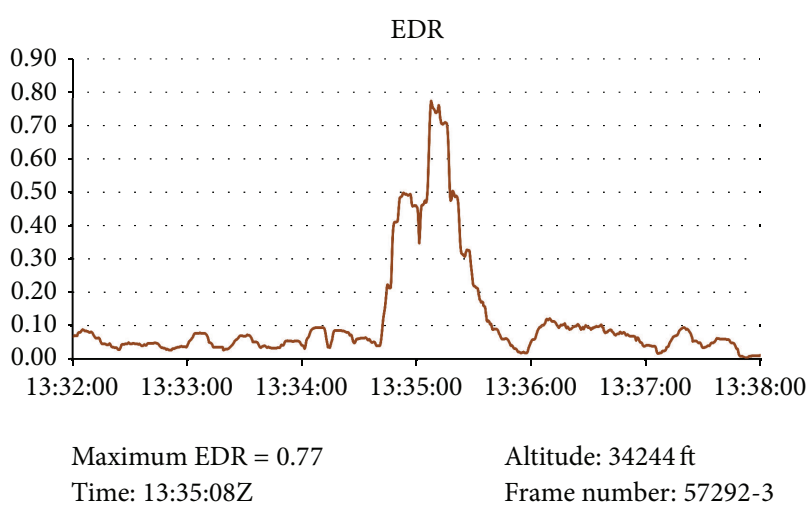

Location: $15.24027 \mathrm{~N} 116.7893 \mathrm{E}$
Altitude: $34244 \mathrm{ft}$

Frame number: 57292-3

(f)

FIGURE 4: Time series of flight data of the A320 aircraft.

[5] in order to derive some quantities which are not available in the standard QAR data storage, such as vertical velocity, eddy dissipation rate (EDR), and windshear hazard factor (Ffactor).

The time series of wind speed and wind direction are shown in Figures 4(a) and 4(b). It could be found that, at the event time, the wind direction changed from easterly to southerly and later on became southeasterly. In this period, there were a number of "pulses" in the wind speed, with the maximum reaching about $15 \mathrm{~m} / \mathrm{s}$, which was much higher than the wind speed of about $5 \mathrm{~m} / \mathrm{s}$ outside the event.

The time series of vertical velocity and F-factor are shown in Figures 4(c) and 4(d), respectively. The aircraft appears to be experiencing strong downdraft in the event, with the downward speed reaching $22 \mathrm{~m} / \mathrm{s}$. There is a very rough windshear condition. The F-factor fluctuated between +0.8 and -0.6 during the event, which is much higher than the conventional threshold of -0.105 for alerting low-level windshear and the threshold of -0.05 as determined from the low-level windshear reports [6].

The altitude of the aircraft and the EDR are shown in Figures 4(e) and 4(f). The aircraft was flying at FL340. During the event, the aircraft first climbed to about 34300 feet $(10390 \mathrm{~m})$ and then lost height significantly to about 33000 feet $(10000 \mathrm{~m}$, a loss of about 1300 feet or $390 \mathrm{~m})$ before climbing back to FL340. The EDR during the event also reached rather high values. There are two peaks in the $\mathrm{EDR}^{1 / 3}$, one reaching $0.5 \mathrm{~m}^{2 / 3} \mathrm{~s}^{-1}$ and the other one even reaching $0.77 \mathrm{~m}^{2 / 3} \mathrm{~s}^{-1}$. According to the thresholds given in ICAO [7], they corresponded to moderate-to-severe turbulence and severe turbulence, respectively.

To better visualize the event, the wind barbs and EDR along the flight route are overlaid on the satellite picture at 


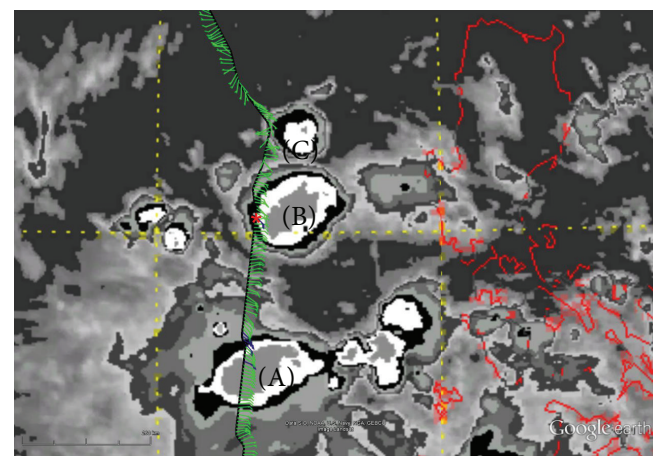

(a)

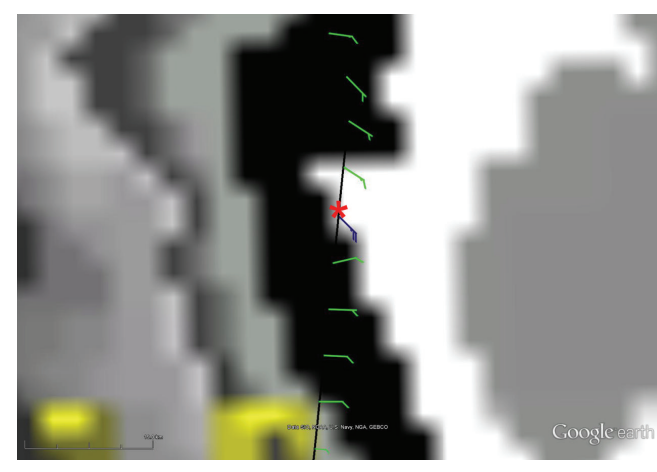

(b)

FIGURE 5: Flight path (from bottom to top) and wind barbs recorded on the aircraft as overlaid on the satellite picture of MTSAT. The asterisk shows the location of the severe turbulence event, (b) is a zoom-in of (a) around the turbulence event location.

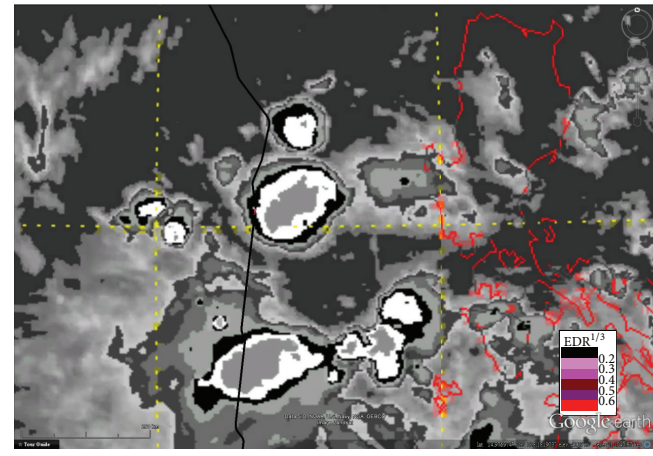

(a)

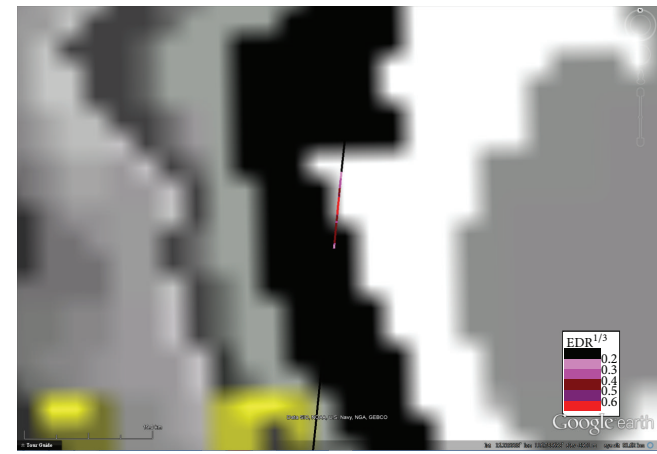

(b)

FIgURE 6: Similar to Figure 5 but for $\mathrm{EDR}^{1 / 3}$, (b) shows a zoom-in of (a) around the location of the turbulence event.

1332 UTC, 9 August 2013. The wind barb picture is shown in Figure 5. It could be seen that the winds gusted up to 20 knots $(10 \mathrm{~m} / \mathrm{s})$ or above inside the convection, at least inside the two areas of significant convection as shown in the figure (areas "A" and "B"). On moving through area " $C$ ", the aircraft was more located at the edge of the convection and the winds were lighter. The wind direction also changed from easterly through southerly to eventually southwesterly near the upper end of Figure 5.

The time series of EDR is overlaid on the satellite picture as shown in Figure 6. The area of significant turbulence was very isolated in terms of spatial coverage. It was located at the western end of the convection area "B." After encountering the significant turbulence, the aircraft appeared to move further westwards in order to avoid the significant convection areas (the remaining part of cluster " $\mathrm{B}$ " as well as cluster "C").

From the satellite imageries and synoptic meteorological data, the turbulence appears to have occurred on the west (downshear) side of the convective anvil. Lane et al. [8] provide a comprehensive overview of the latest understanding of near-cloud turbulence. In particular, the severe turbulence occurring in the unstable upper-level thunderstorm overflow appears to be consistent with the turbulence event as reported in this paper. Further study would be carried out, for example, using high resolution numerical weather prediction model, to understand the mechanism of the severe turbulence in the present event, especially if this turbulence event is related to the upper-level thunderstorm outflow. For instance, the large eddy simulation in a way similar to Ahmad and Proctor [3] may be employed. The present case differs very much from those convection-induced turbulence events as reported in Ahmad and Proctor [3] in that the significant turbulence occurs downwind, instead of upwind, of the convection.

\section{Performance of Aviation Products from WAFC}

Cumulonimbus (CB) and turbulence products are available from World Area Forecast System (WAFS) for flight planning purpose. They are provided by World Area Forecast Centres (WAFCs) London and Washington and are available as gridbased products. The list of available products could be found in ICAO [7]. In this section, only the products from WAFC London are discussed, and they are not very different from those from WAFC Washington due to harmonization of products from the two centres.

The $\mathrm{T}+24$ and $\mathrm{T}+27$ forecast products based on the model run at 12 UTC, 8 August 2013, are considered. The CB horizontal extent is given in Figure $7(\mathrm{a})$. The forecast extent 


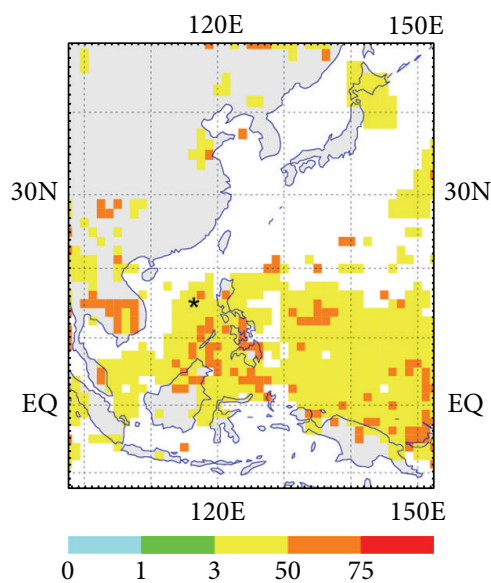

(\%)

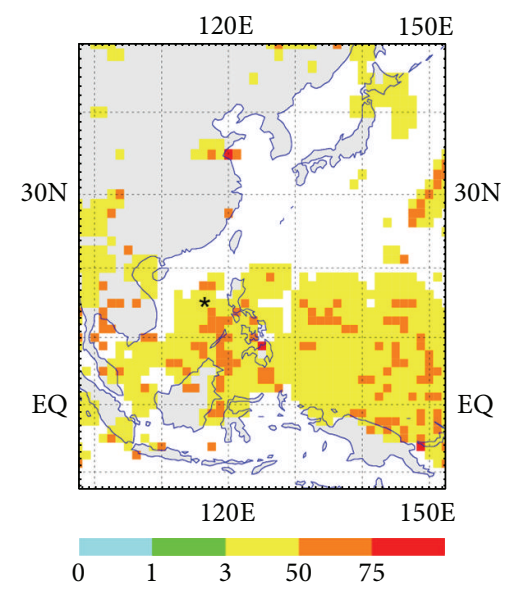

(\%)

(a) CB horizontal extent

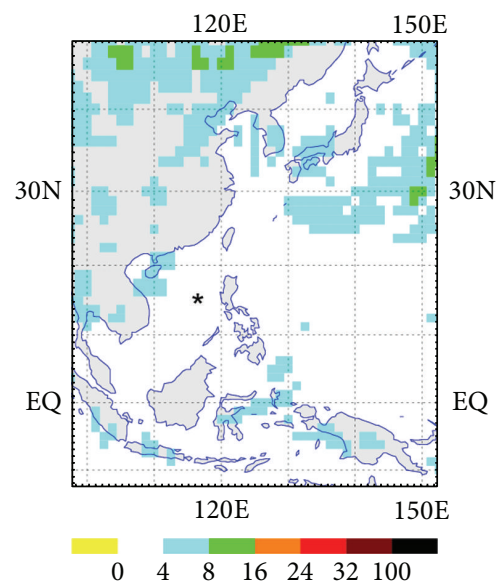

(\%)

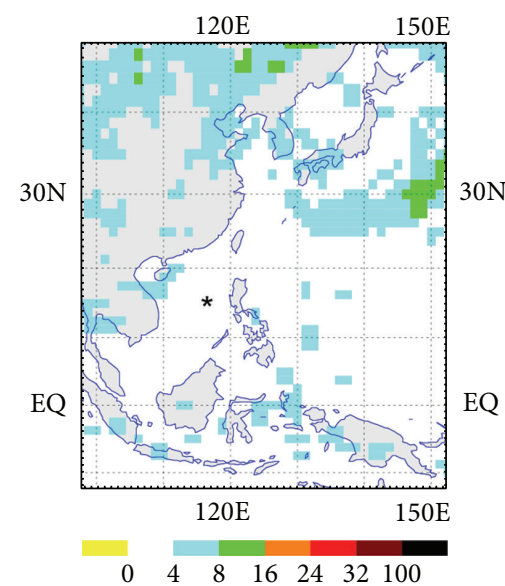

(\%)

(b) CAT potential at FL340

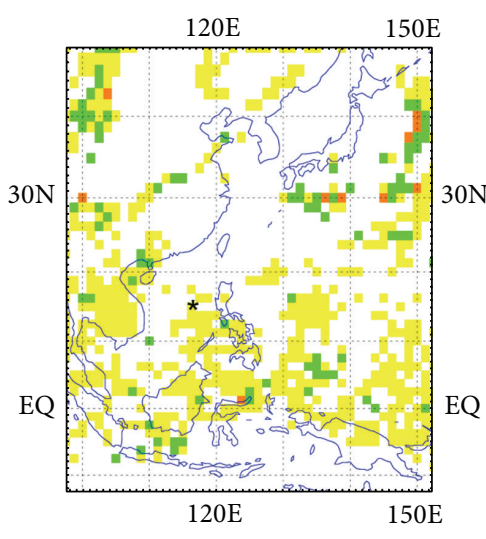

(\%)

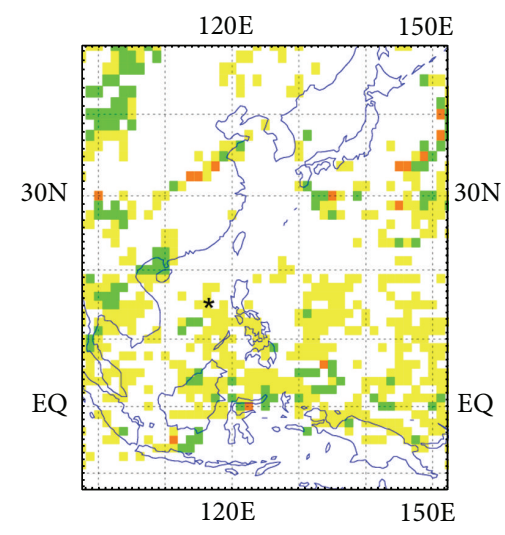

(\%)

(c) In-cloud turbulence potential at FL300

Figure 7: Selected products from WAFC London based on the model run at 12 UTC, 8 August 2013. The forecast times at T+24 are shown on the left hand side and at $\mathrm{T}+27$ on the right hand side. The asterisk shows the location of the turbulence event. 


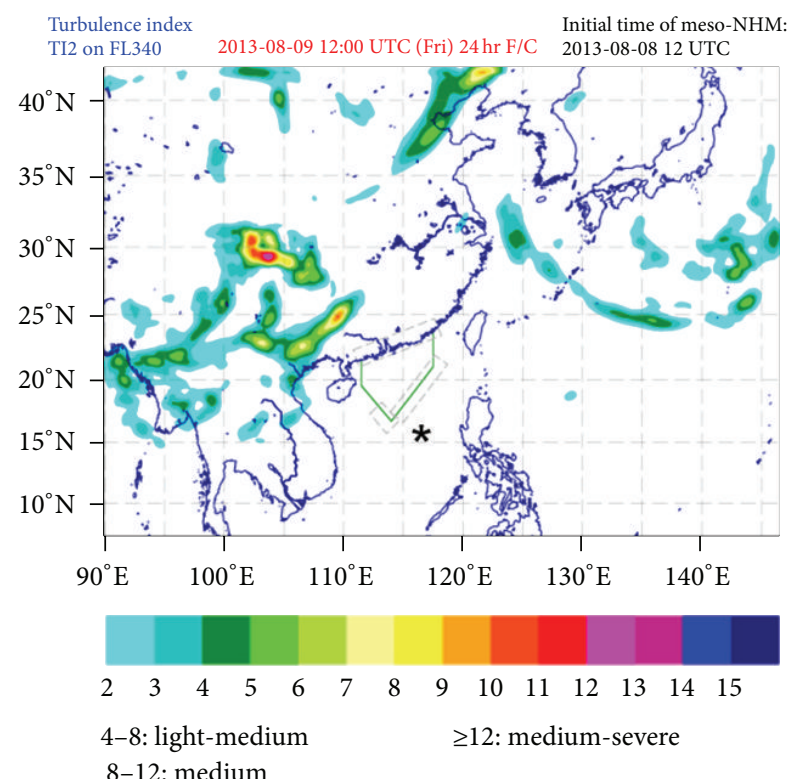

(a)

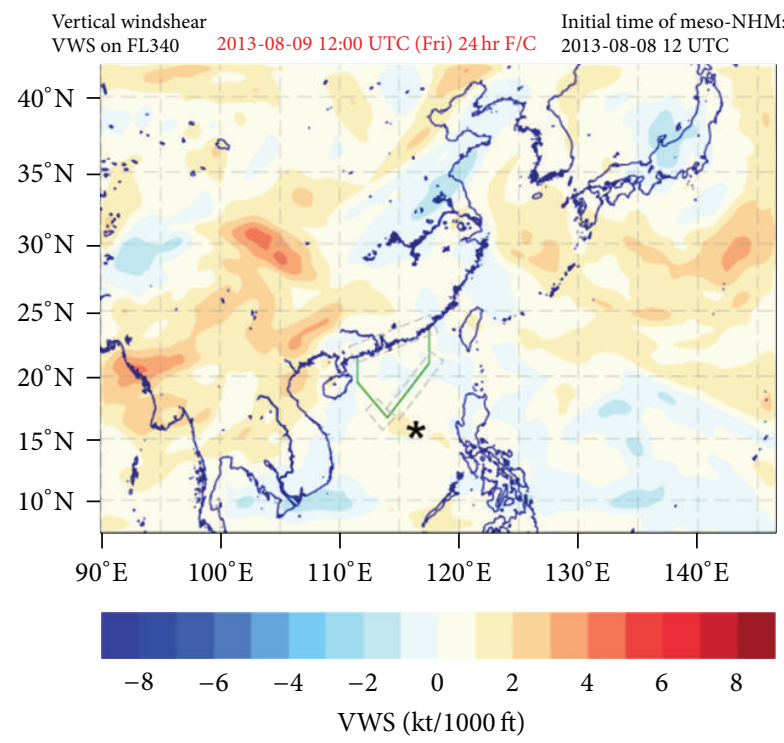

(c)

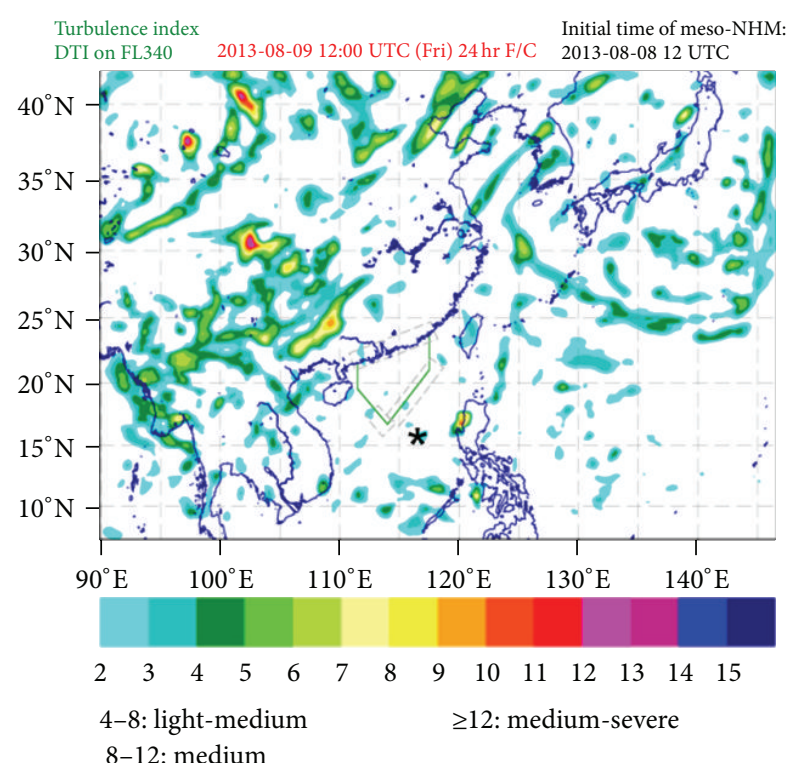

(b)

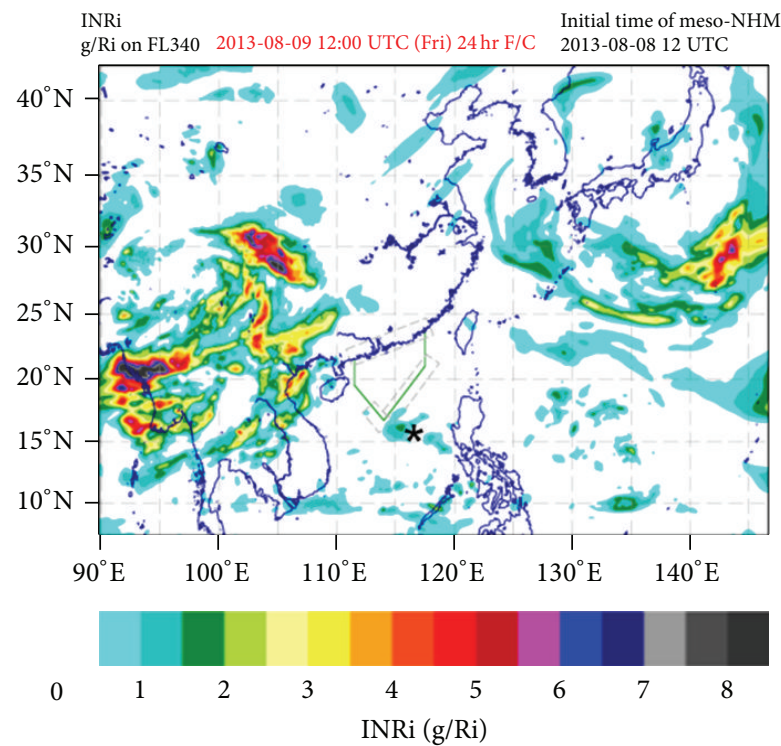

(d)

FIGURE 8: T+24-hour forecast TI (a), DTI (b), VWS (c), and INRi (d) based on NHM run at 12 UTC, 8 August 2013. The asterisk shows the location of the turbulence event.

of CB over the central part of the South China Sea is generally satisfactory in comparison with actual observations from, say, satellite pictures. The clear air turbulence (CAT) forecast products at the same times at FL340 are shown in Figure 7(b). There is no signature of significant turbulence in the area of the present case of severe turbulence encounter.

For in-cloud turbulence, the highest altitude with forecast product available is FL300, and the products at the two forecast times are shown in Figure 7(c). There are a couple of grid points with in-cloud turbulence potential of 0.2 to $2 \%$. Based on the present case of severe turbulence encounter, maybe this level of in-cloud turbulence should already be considered to be significant for flight planning purpose. More statistics should be collected around the world to interpret the results of the in-cloud turbulence potential.

\section{Forecast of Turbulence Intensity Using Mesoscale NWP Model}

Several model products on turbulence intensity guidance are made from the outputs of the nonhydrostatic model (NHM) in $\mathrm{HKO}$ for reference by the aviation forecasters. NHM system is operated with horizontal resolution of $10 \mathrm{~km}$ to provide forecast up to 72 hours with initial conditions provided from the 3DVAR analysis running in 3-hour update cycle. For details of the model configurations refer to Wong et al. [9] and 


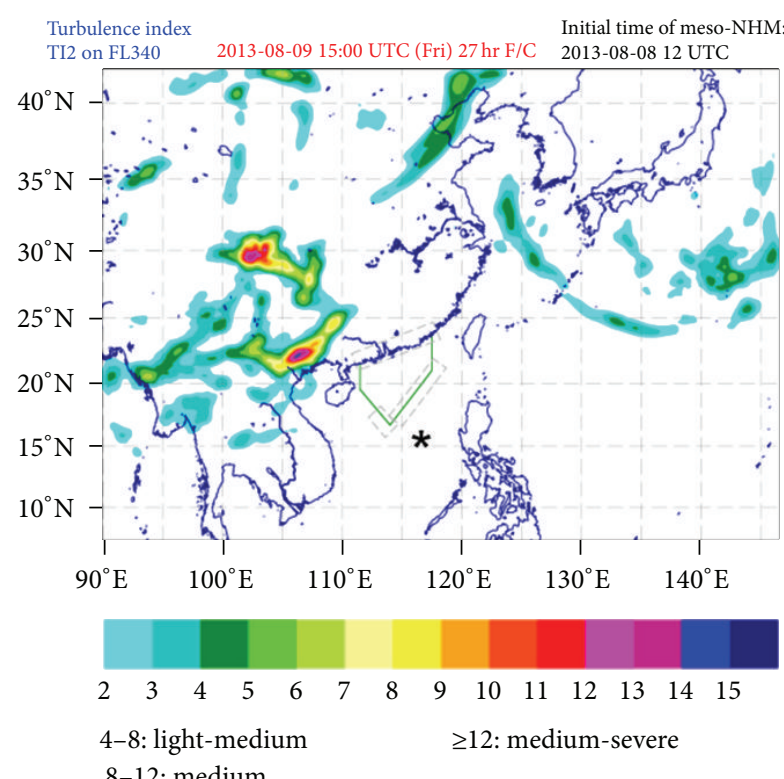

(a)

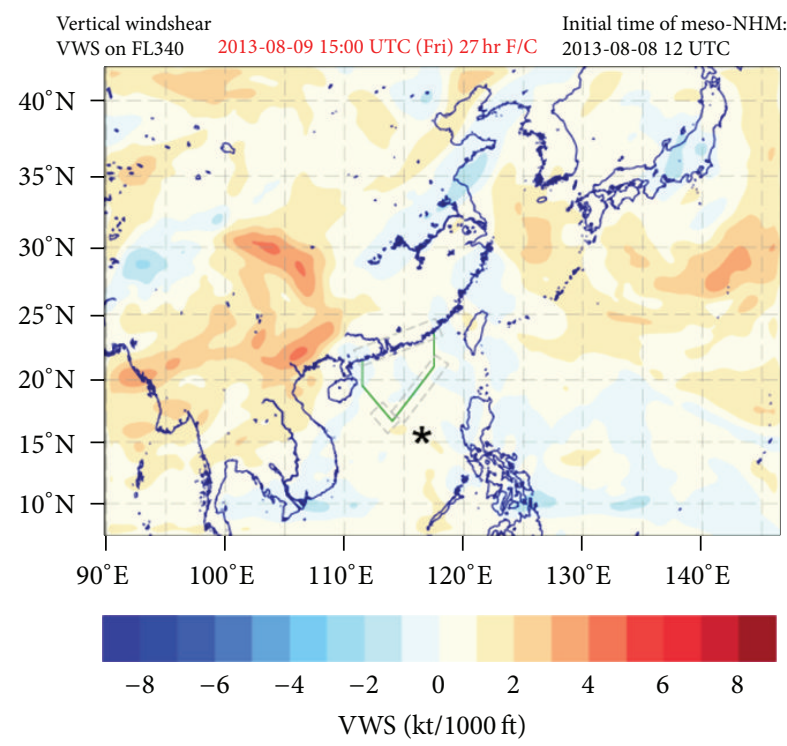

(c)

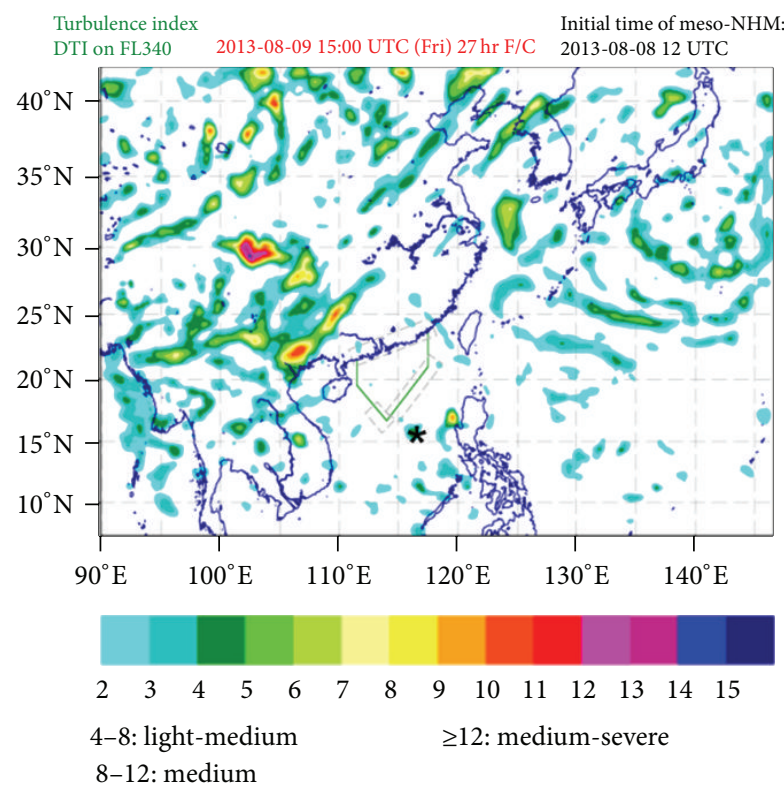

(b)

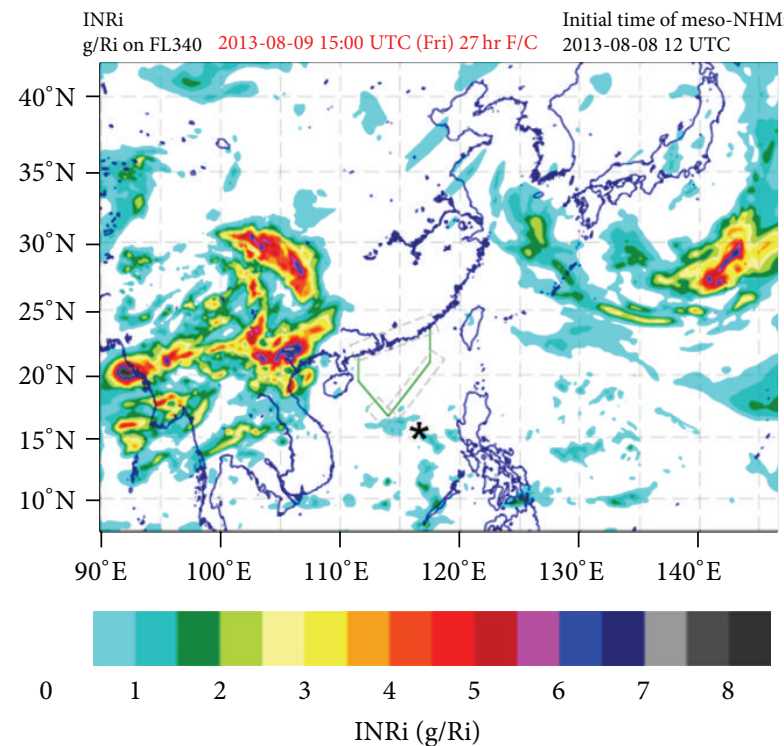

(d)

FIGURE 9: Similar to Figure 8 but for T+27-hour forecast. The asterisk shows the location of the turbulence event.

NHM is originally developed by the Japan Meteorological Agency [10]. Figures 8 and 9 show the gridded forecasts of Ellrod's turbulence index (TI2), divergence modified turbulence index (DTI) [11], vertical windshear (VWS), and the inverse of bulk Richardson number (INRi) from NHM. At each grid point with resolution of 0.1 degrees in both latitude and longitude, the four indices are calculated according to the following formulas:

$$
\begin{gathered}
\operatorname{VWS}=\frac{\Delta V}{\Delta z}, \\
\mathrm{INRi}=\frac{g}{\left((1 / \theta \times(\Delta \theta / \Delta z)) / \mathrm{VWS}^{2}\right)},
\end{gathered}
$$

$$
\begin{gathered}
\mathrm{TI}=\mathrm{VWS} \times(\mathrm{DEF}-\mathrm{DIV}), \\
\mathrm{DTI}=\mathrm{VWS} \times \mathrm{DEF}+\alpha\left(\mathrm{DIV}_{t 2}-\mathrm{DIV}_{t 1}\right),
\end{gathered}
$$

where $V$ is the magnitude of horizontal wind vector, $z$ is the height, $\theta$ is the potential temperature, DEF is the deformation that is a sum of stretching and shearing deformation terms, and DIV is the divergence. TI is also referred to as Ellrod's TI2 index [12]. Physically, DTI accounts for effects of rapid changing divergent flow conducive to the occurrence of turbulence. The temporal change of DIV at two time levels $t 1$ and $t 2(t 2>t 1)$ is multiplied by a coefficient $\alpha$ in order to give a similar order of magnitude to the first term (also known as Ellrod's TIl index) on the right hand side of (4). 


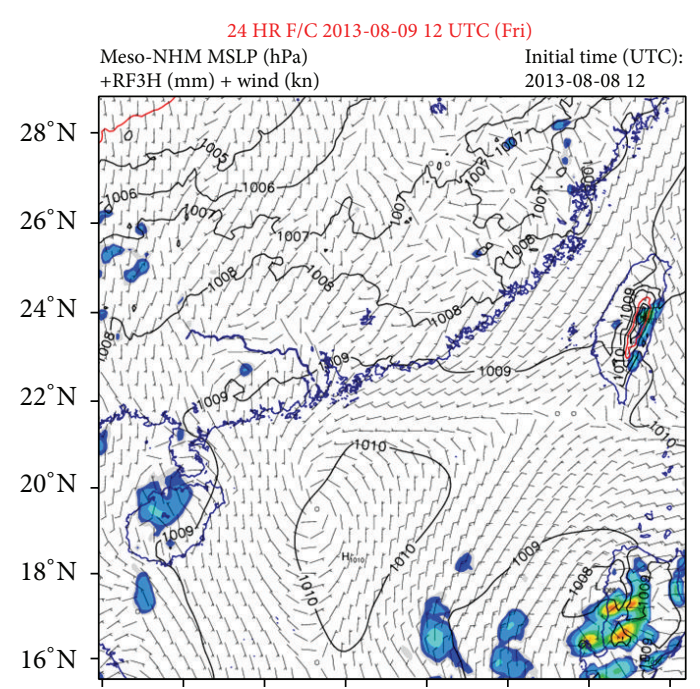

$108^{\circ} \mathrm{E} 110^{\circ} \mathrm{E} 112^{\circ} \mathrm{E} 114^{\circ} \mathrm{E} 116^{\circ} \mathrm{E} 118^{\circ} \mathrm{E} 120^{\circ} \mathrm{E} 122^{\circ} \mathrm{E}$
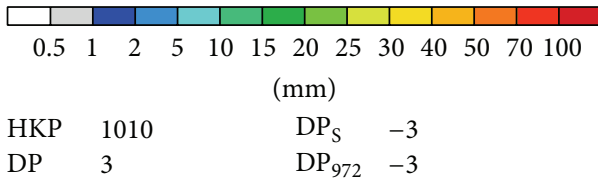

(a)

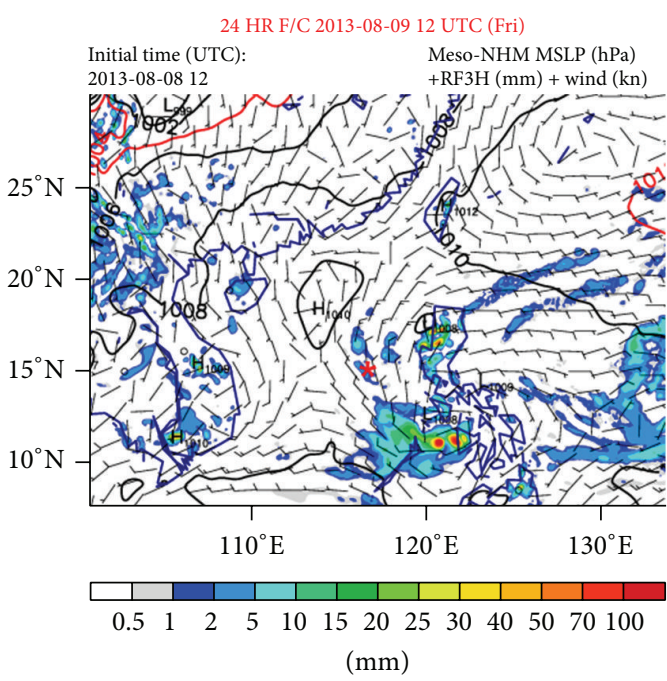

(c)

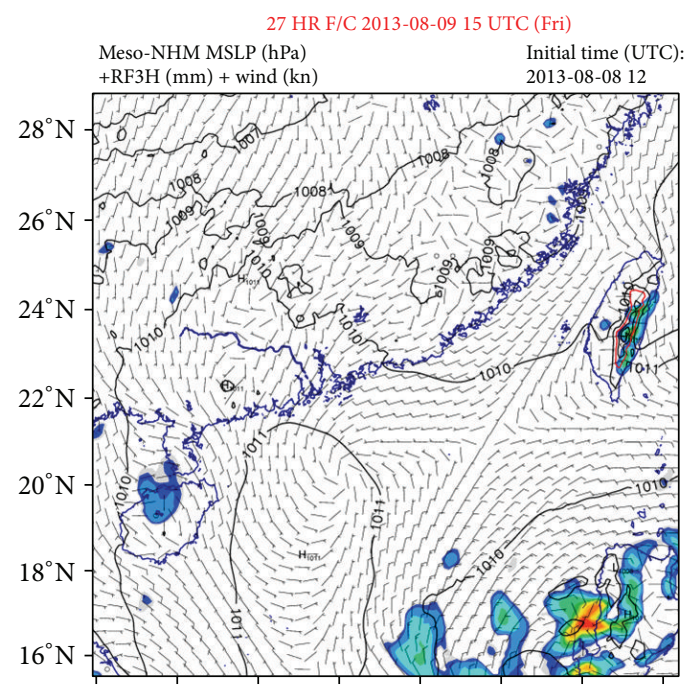

$108^{\circ} \mathrm{E} 110^{\circ} \mathrm{E} 112^{\circ} \mathrm{E} 114^{\circ} \mathrm{E} 116^{\circ} \mathrm{E} 118^{\circ} \mathrm{E} 120^{\circ} \mathrm{E} 122^{\circ} \mathrm{E}$

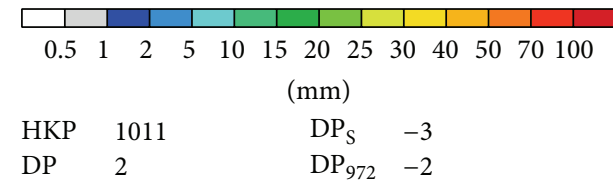

(b)

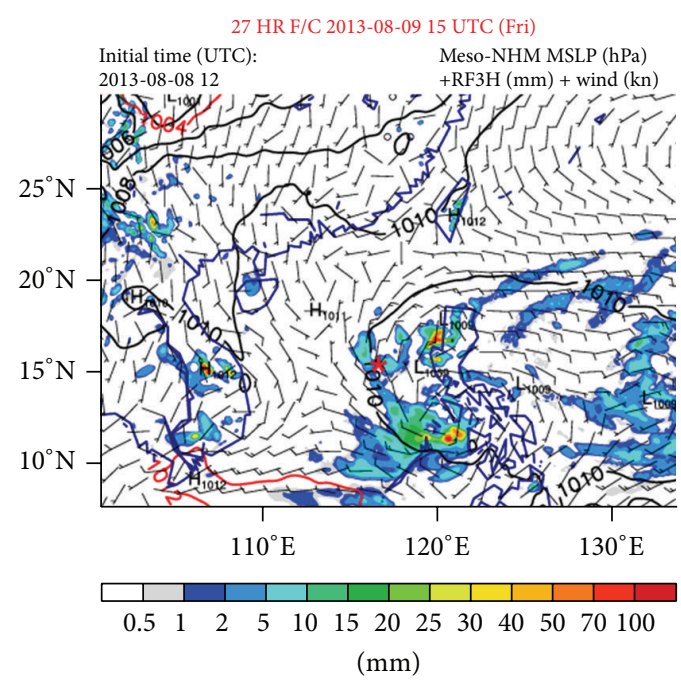

(d)

FIGURE 10: $\mathrm{T}+24$-hour and $\mathrm{T}+27$-hour forecast of surface wind, mean sea level pressure (contour), and 3-hour accumulated rainfall (shaded) from NHM run at 1200 UTC, 8 August 2013. The asterisk shows the location of the turbulence event.

In calculation of DTI using NHM forecasts, model forecasts at 3-hour time intervals are used. About half year of past model data in 2010 have been used and compared to the actual turbulence intensity from pilot reports over the Hong Kong Flight Information Region and southern China to tune the parameter $\alpha$.

The $\mathrm{T}+24$ and $\mathrm{T}+27$ forecast TI, DTI, VWS, and INRi based on the model run at 12 UTC, 8 August 2013, are shown in Figures 8 and 9, respectively. Over the areas of event location that are near to the southern boundary of the Hong
Kong Flight Information Region (HKFIR, shown in the green line polygon), there is an indication of turbulent potential from the VWS and INRi (panels in the lower row) though not very significant. Moreover, the model forecast suggests a nonzero VWS with a layer of unstable environmental flow (small static stability) at FL340. The horizontal shear deformation and stretching deformation are not significant; hence, there is no sign of turbulence indicated in forecast TI (top left panel). In DTI (top right panel), there are two local maxima with one near the event location in $\mathrm{T}+27$ forecast and 


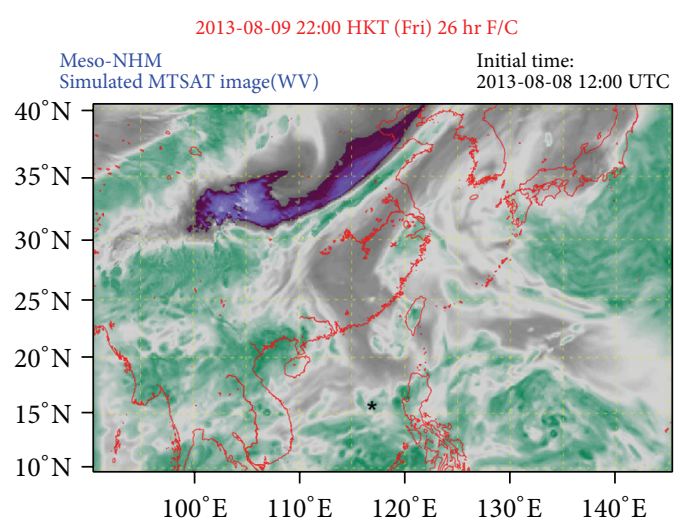

(a)

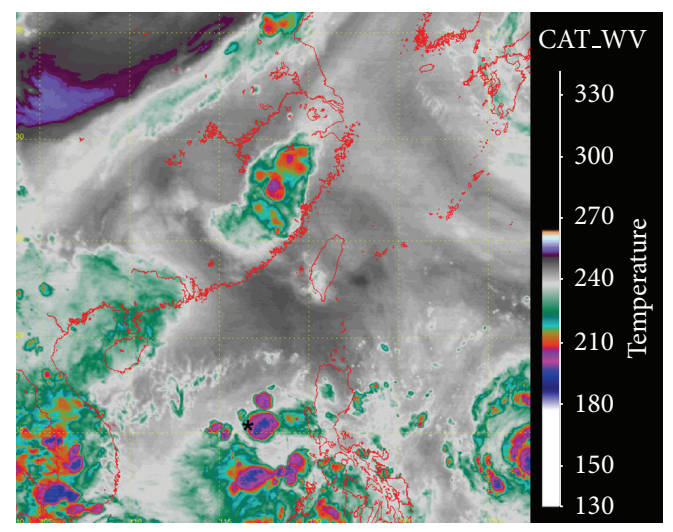

(b)

FIGURE 11: Simulated water vapour image (a) at 1400 UTC, 9 August 2013, and MTSAT image (b) at 1332 UTC. The asterisk shows the location of the turbulence event.

other over the western coast of Luzon at both 1200 and 1500 UTC. The high forecast DTI (medium level of turbulence intensity) is due to increase in horizontal divergence on upper tropospheric level over the preceding three hours at 1200 UTC and 1500 UTC, which are closely related to convective development over the region according to the model forecast (Figure 10). To further exemplify the convective development, simulated water vapour channel image using NHM forecasts and the RTTOV radiative transfer model [13] as the forward operator is shown in Figure 11. It is found that the model simulated brightness temperature compared reasonably with the actual satellite image in terms of coverage of cloud. Several clusters of low brightness temperature are simulated by the model over Luzon and the event area.

It may be difficult to use any of the NWP products to anticipate a severe turbulence hazard on the route, with possible exception of Figure 7(a). Onboard radar and rapid access to satellite imagery would have been the key tools for turbulence avoidance.

\section{Conclusion}

A case of severe turbulence encountered by an aircraft over the South China Sea is documented in the present paper. It is rather rare to have significant turbulence over the South China Sea, though it is a rather busy air traffic area. The present study is valuable in that full set of flight data are available from the aircraft to analyze the event, not only the conventional wind speed and wind direction, but also the vertical velocity, windshear hazard factor, and EDR.

From the available QAR data, the severe turbulence was associated with large increase in wind speed, strong downdraft, high value of F-factor, and, most importantly, $\mathrm{EDR}^{1 / 3}$ reaching severe turbulence level. This case once again illustrates the possible applicability of a threshold of $0.7 \mathrm{~m}^{2 / 3} \mathrm{~s}^{-1}$ for severe turbulence for enroute aircraft. By overlaying the flight data on the infrared satellite picture, the severe turbulence appears to be associated with significant and developing convection reaching the flight level, and it is rather isolated in spatial extent. It is not clear why the pilot was not alerted of significant convection and severe turbulence based on the data collected by the onboard weather radar due to unavailability of the radar record.

The performance of NWP model in the alerting of this severe turbulence event is also analyzed. For products from WAFS, the CB horizontal extent and in-cloud turbulence potential turn out to be quite useful in indicating the possible occurrence of significant turbulence associated with convection in the area concerned, though the in-cloud turbulence potential seems to be on the low side. The WAFS CB product has been verified over a large, non-Asian region by Mirza [14]. A mesoscale NWP model is capable of forecasting the occurrence of moderate-to-severe turbulence over the area as far as 24 to 27 hours in advance. Of course, the performance of these turbulence products would need to be evaluated using a larger dataset.

It is hoped that more flight data from similar cases could be made available to the aviation meteorological community so that the characteristics of severe turbulence over the South China Sea could be better understood. This would also be useful for assessing the performance of NWP-based turbulence products in the region.

\section{Conflict of Interests}

The authors declare that there is no conflict of interests regarding the publishing of this paper.

\section{References}

[1] W. T. Roach and C. E. Bysouth, "How often does severe clear air turbulence occur over tropical oceans?" Weather, vol. 57, pp. 8-19, 2002.

[2] T. N. Rao, B. Radhakrishna, T. M. Satyanarayana, and S. S. Kumar, "The exchange across the tropical tropopause in overshooting convective cores," Annales Geophysicae, vol. 28, no. 1, pp. 113-122, 2010. 
[3] N. Ahmad and F. Proctor, "Large eddy simulations of severe convection induced turbulence," in Proceedings of the 3rd AIAA Atmospheric Space Environments Conference, Honolulu, Hawaii, USA, June 2011.

[4] C. Velden, B. Harper, F. Wells et al., "The Dvorak tropical cyclone intensity estimation technique: a satellite-based method that has endured for over 30 years," Bulletin of the American Meteorological Society, vol. 87, no. 9, pp. 1195-1210, 2006.

[5] H. Haverdings and P. W. Chan, "Quick access recorder data analysis software for windshear and turbulence studies," Journal of Aircraft, vol. 47, no. 4, pp. 1443-1446, 2010.

[6] P. W. Chan, "Application of LIDAR-based F-factor in windshear alerting," Meteorologische Zeitschrift, vol. 21, pp. 193-204, 2012.

[7] International Civil Aviation Organization (ICAO), Annex 3 to the Convention on International Civil Aviation: Meteorological Service for International Air Navigation, 2010.

[8] T. P. Lane, R. D. Sharman, S. B. Trier, R. G. Fovell, and J. K. Williams, "Recent advances in the understanding of near-cloud turbulence," Bulletin of the American Meteorological Society, vol. 93, pp. 499-515, 2012.

[9] W. K. Wong, P. W. Chan, and C. K. Ng, "Aviation applications of a new generation of mesoscale numerical weather prediction system of the Hong Kong Observatory," in Proceedings of the 24th Conference on Weather and Forecasting and 20th Conference on Numerical Weather Prediction, American Meteorological Society, Seattle, Wash, USA, January 2011.

[10] K. Saito, T. Fujita, Y. Yamada et al., "The operational JMA nonhydrostatic mesoscale model," Monthly Weather Review, vol. 134, no. 4, pp. 1266-1298, 2006.

[11] G. P. Ellrod and J. A. Knox, "Improvements to an operational clear-air turbulence diagnostic index by addition of a divergence trend term," Weather and Forecasting, vol. 25, no. 2, pp. 789-798, 2010.

[12] G. P. Ellrod and D. I. Knapp, "An objective clear air turbulence forecasting technique: verification and operational use," Weather Forecasting, vol. 7, pp. 150-165, 1992.

[13] R. Saunders, M. Matricardi, and P. Brunel, "An improved fast radiative transfer model for assimilation of satellite radiance observations," Quarterly Journal of the Royal Meteorological Society, vol. 125, no. 556, pp. 1407-1425, 1999.

[14] A. Mirza, "Objective verification of manual, automated and harmonised forecasts of cumulonimbus clouds from the World Area Forecast Centres," in Proceedings of the 6th Conference on the Meteorological Applications of Lightning Data, American Meteorological Society, January 2013. 

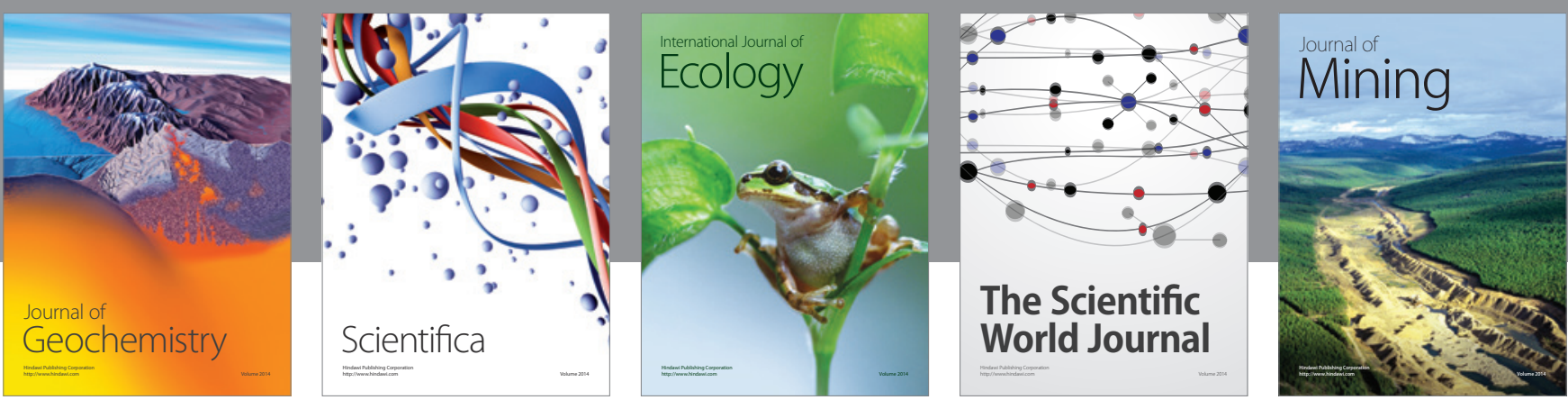

The Scientific World Journal
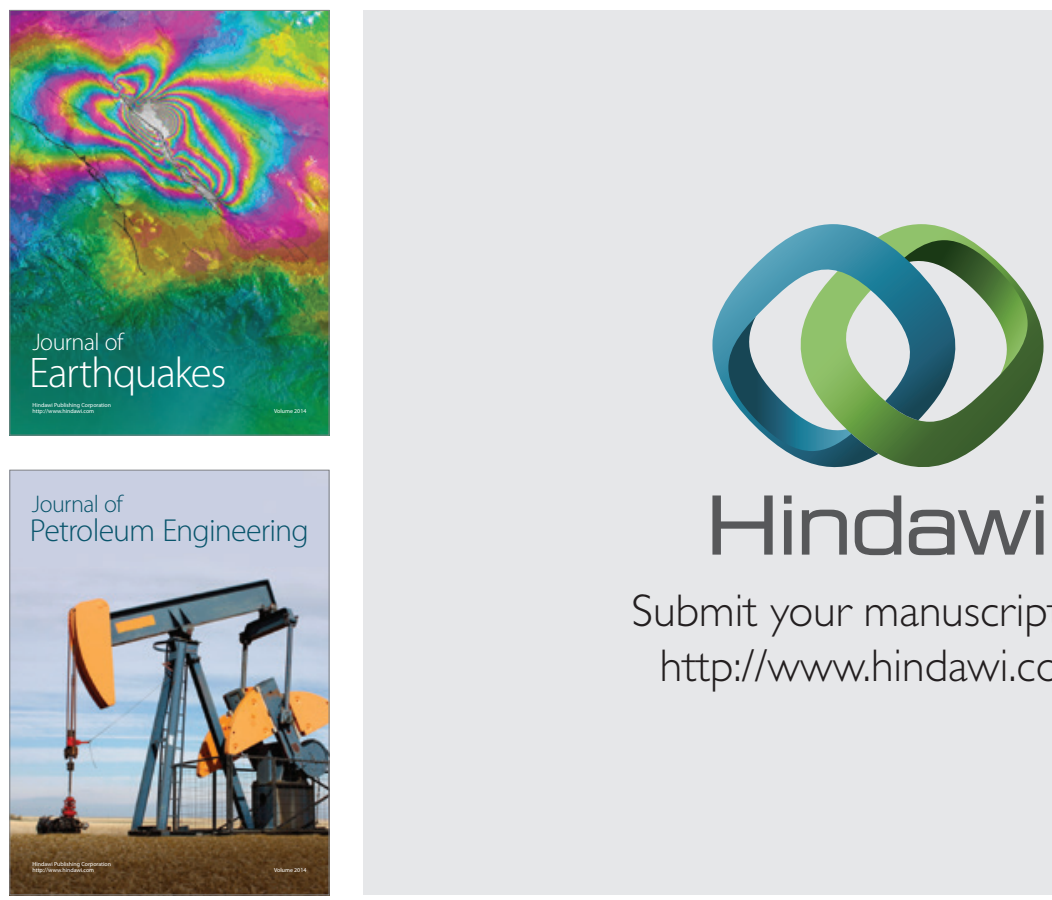

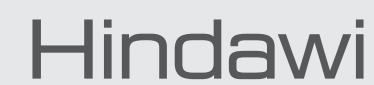

Submit your manuscripts at

http://www.hindawi.com
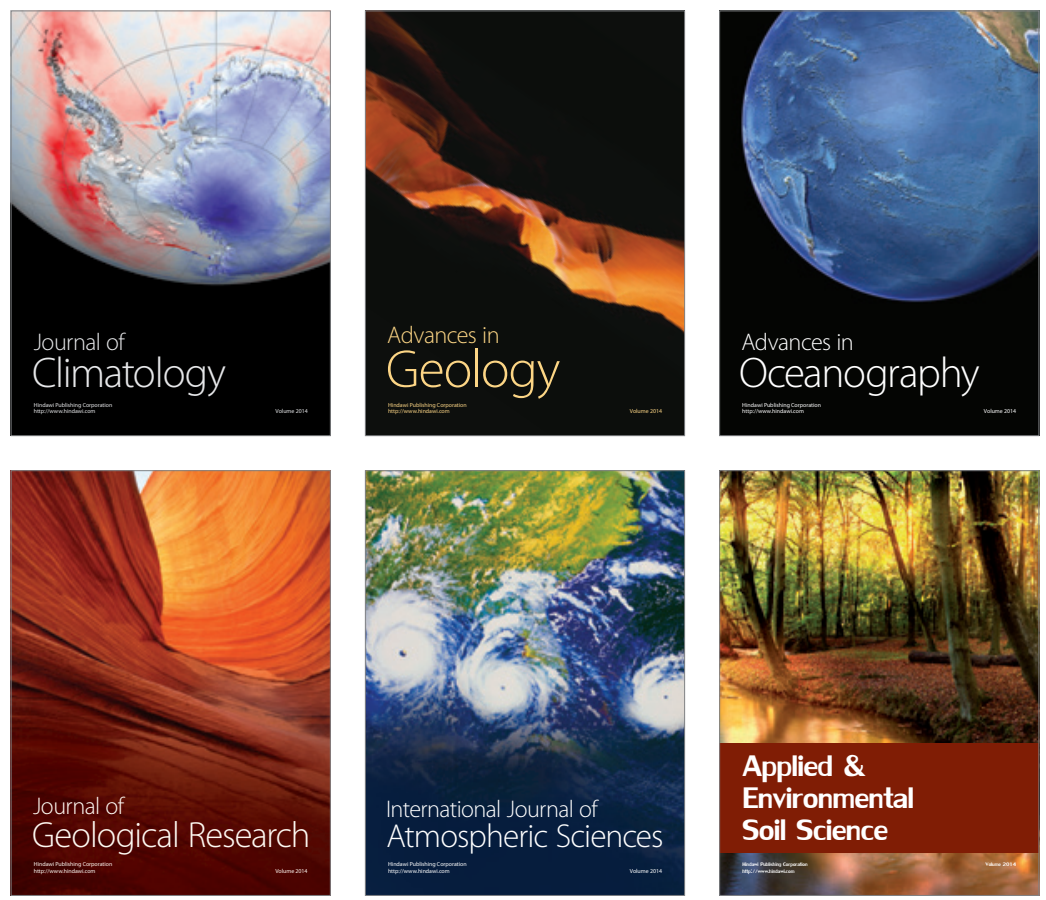
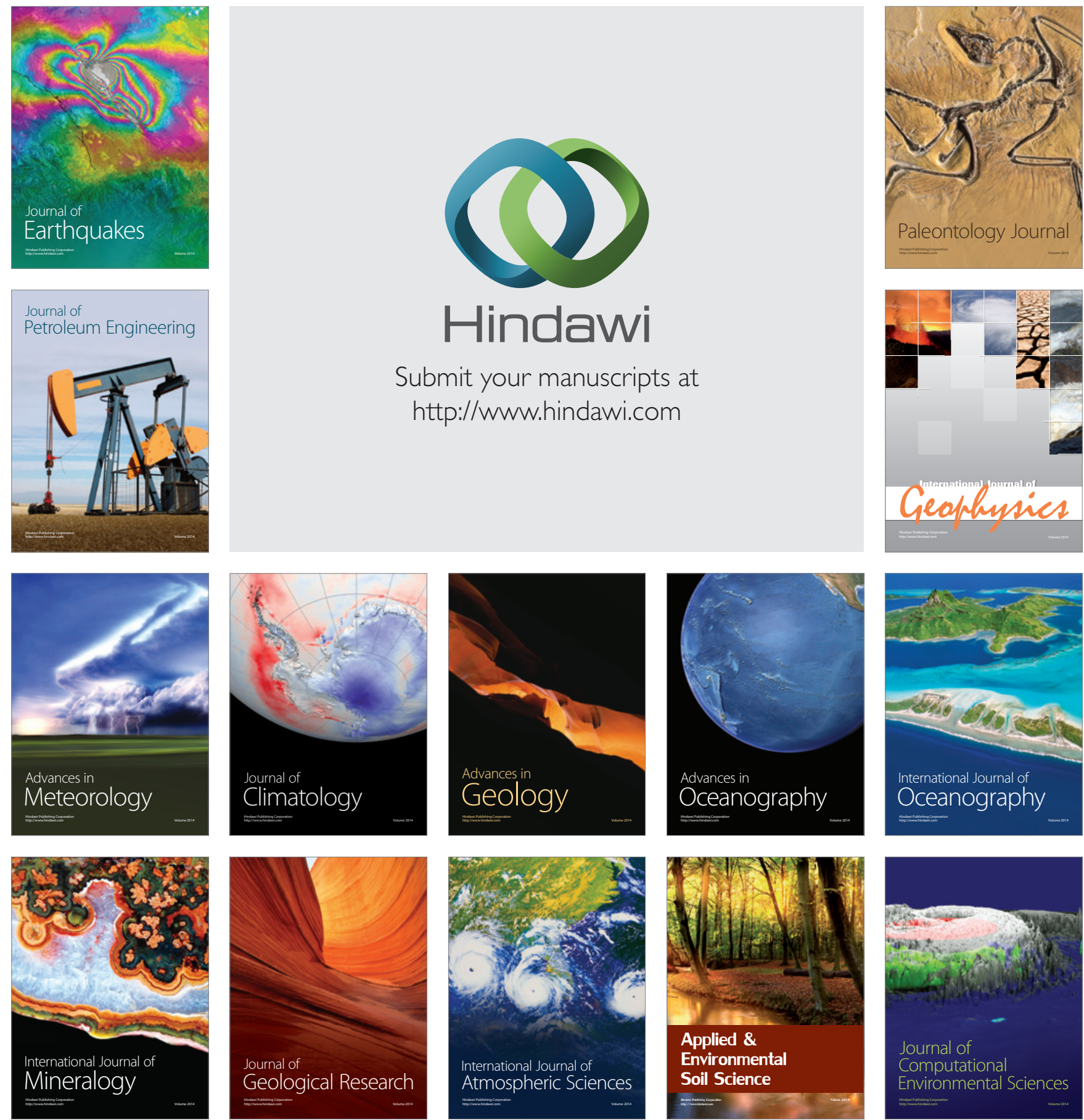